\title{
Study the Effect of Oil Viscosity on Friction Coefficient at Point Contact Elasto-Hydrodynamic Lubrication Based on Experimental Analysis
}

\author{
Hassan S. Fatehallah ${ }^{1}$, Zaid S. Hammoudi ${ }^{2}$, Lutfy Y. Zidane ${ }^{3}$ \\ ${ }^{1,2,3}$ Department of Mechanical Engineering, College of Engineering-University of Diyala \\ *corresponding author: email address: eng.has8san@gmail.com
}

\begin{abstract}
This study presents an experimental work for elastohydrodynamic lubrication (EHL) in point contact case. In this study, experimental studies have been conducted to show how friction varies over a wide range of running conditions. The effect of the change in parameters such as lubricant's viscosity, base oil type, and load on power loss is investigated. The oils have used $(5 \mathrm{~W}-20,10 \mathrm{~W}-30,10 \mathrm{~W}-$ 40 and 20W-50) which have a different grade of viscosity. The test is conducted using a ball on disc test rig. Different loads have been used $(30,40,50$, and $60 \mathrm{~N})$. The boundary conditions are: the oil's temperature is $\left(25^{\circ} \mathrm{C}\right.$ temperature room); the radius of ball is $(0.018 \mathrm{~m})$. The coefficient of friction of oils for each load has been calculated. At the same load and same initial conditions the results shows, the increase in friction coefficient with the increase of viscosity is almost linear with an average slope of 1.4 $(\mathrm{Pa} . \mathrm{s})^{-1}$. Also, the increase in load results in linear increase in friction coefficient by an average slope of $0.63 \mathrm{~N}^{-1}$.
\end{abstract}

Keywords: Elasto-hydrodynamic lubrication; Point contact; Ball on disc machine; Friction coefficient.

Paper History: (Received:4-4-2019; Accepted:23-102019)

\section{INTRODUCTION}

Wear and friction can be noted in different places in our everyday life. They occur whenever two components in contact, with a relative motion on each other. In mechanical system wear and friction generally, appear harmfully at many levels. Friction leads to increase energy consumption of the system, whereas wear can decreases system life. Therefor it is important to minimize the effect of those factors, in any mechanical system [1]. The most known way to reduce friction is lubrication. When two surfaces are in contact, the lubricant film separated it. Generally, there are three lubrication regimes, defined according to their range of coefficient of friction, boundary lubrication, mixed lubrication, and full film lubrication [2].

The first systematic implementation of disc machine measurements for studying elastohydrodynamic friction was be obvious in the 1960s. Many researches focus on friction in elasto-hydrodynamic lubrication [3]; find out, among others, bearings, gears, and cam followers. Wang WZ, et al [4] presented a numerical approach to simulate sliding friction between engineering surfaces with (3D) roughness in point contacts. They use 'Universal Material
Tester' (UMT) to measure friction at a fixed load, and different sliding velocities in reciprocal or rotary motions.

Björling Marcus [5, 6] used the MTM testing machine in his experimental studies. He has showed how friction varies over a wide range of running conditions when changing parameters like; lubricant viscosity, base oil type, surface roughness and lubricant temperature. Also they used these measurements to predict the friction behavior in a real gear application.

Roland L, et al [7] made a friction test in a ball on disc test rig. In addition, they calculated the friction coefficient with speed and slide to roll ratio (SRR). They made a test with a number of parameters that varied while studying the friction coefficient, such as; surface roughness, oil viscosity, oil temperature, and slide to roll ratio. The results of this study show that the mapping is efficient for showing the different types of friction that may occur in an EHL contact. Moreover, show that the friction behavior can be strongly influenced by changing; surface roughness, base oil viscosity, EP additive content, and operating temperature.

Cousseau $\mathrm{T}$, et al [8] used three different lubricating greases and their bleed and base oils, were compared in terms of film thickness in a ball on disc test rig, through optical interferometry. They use Hamrock's equation [9] in the theoretical part to calculate the film thickness the result shows a good agreement with that oil film thickness that measures.

N D Laurentis, et al [10, 11] have used a laboratory tribometers to measure friction coefficient and film thickness of a series of commercially available bearing greases and their bled oils.

In this study, mainly interest is the full film lubrication, when the contacting surfaces are completely separated by a lubricant film. This regime have two types of lubrication, Hydrodynamic lubrication (HD) and Elasto-hydrodynamic lubrication (EHL) [12]. This study is focus on the second type (EHL), according to the contact shape there are two types of elastohydrodynamic problems, line contact and point contact. The line contact is represented as a cylinder on the flat surface. Where the ball on disc test rig that used in this study are represented as a point contact problem, as show in figure (1) [13]. 
The aim of the research is to Studying the phenomenon of EHL, for the conditions of highly loaded point contact problem, to measure the friction coefficient using number of engine oils as a lubricant. In this study, a ball on disc test rig has been used with different oils as a lubricant, where it have different viscosity grades $(5 \mathrm{w}-20,10 \mathrm{w} 30,10 \mathrm{~W} 40$, and 20w50). The test has been done in a room temperature and the friction force and coefficient of friction have calculated for each oil, in different applied load $(30,40,50$, and $60 \mathrm{~N}$ ).

$$
R^{-1}=R_{1}^{-1}+R_{2}^{-1}
$$

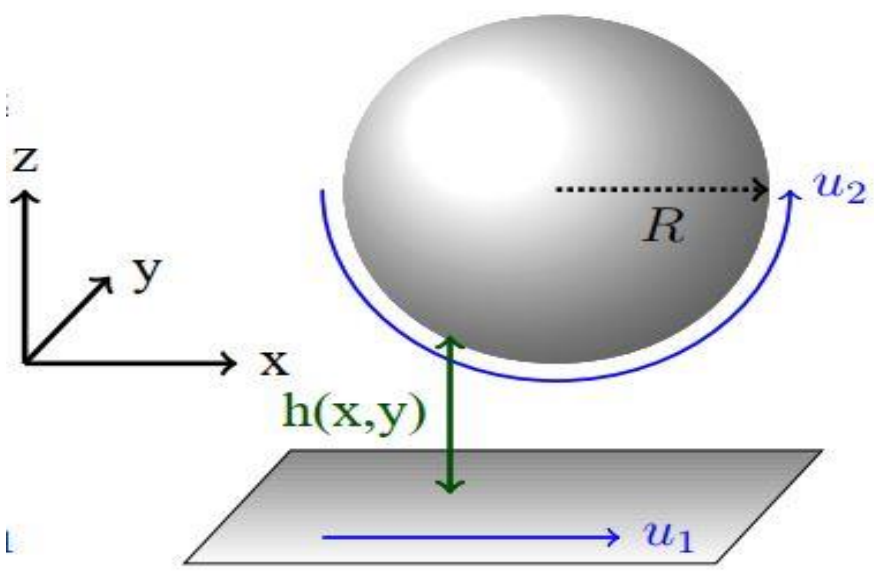

Fig (1) Equivalent reduced geometry of EHL point contact [13].

\section{TEST RIG}

A test rig for the analysis of point contact Elastohydrodynamic lubrication is constructed, in which a steel ball is loaded against a steel disc. Where the test rig is consists of steel ball, steel disc, motor, shaft, arm and frame, and its shown in Figure (2). The disc is connected to a rotary motor by a pulley and solid shaft. The ball is fixed on the rotary disc and it does not rotate (U2=0). An oil dispenser supplies the oil to the disc, and it is contained on the disc by the oil container. The arm is settled on the rig frame, and it is free to rotate right and left. The normal load (w) is applied vertically over the arm. The load cell is mounted on side of arm with the direction of disc rotation, to reading the friction force $(\mathrm{F})$.

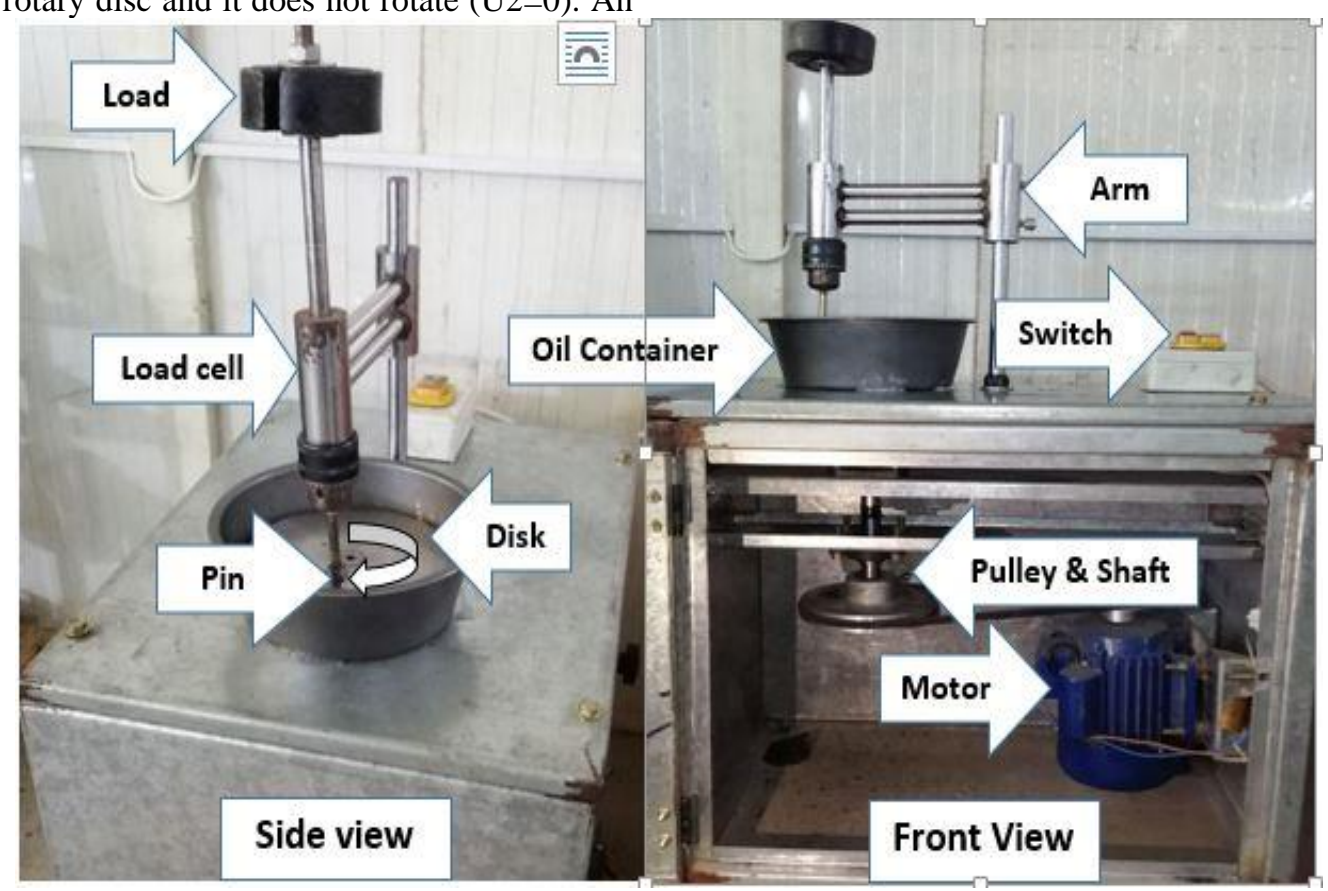

Fig (2) The test rig components. 


\section{TEST CONDITIONS AND PROSEDURE}

The disc is made of steel which has young modulus $(210 \mathrm{GPa})$, and poisons ratio $(0.33)$. The radius of the disc equal $(15 \mathrm{~cm})$. The ball is also made of steel which it young modulus is $(210 \mathrm{GPa})$, the poisons ratio $(0.33)$. The ball radius equal $(18 \mathrm{~mm})$. A steel shaft, connected with the rotary motor, rotate at 600 r.p.m, $(2.5 \mathrm{~m} / \mathrm{s})$, drives the disc. The ball is fixed and its velocity equal zero.

In analyzing an elastohydrodynamic contact, there are two important and very different speeds. The first is mean of rolling speeds $(\mathrm{u}=1.25 \mathrm{~m} / \mathrm{s})$ of two surfaces, with respect to the contact, and it given by [14]:

$$
u=\frac{u 1+u 2}{2}
$$

The second speed is sliding speed, which is the velocity of two surfaces relative to each other, and it given by [14]:

$u_{s}=|u 1-u 2|$
In elastohydrodynamic lubrication, the slide to roll ratio (SRR), which is the ratio of the two velocities, is usually employed, and it is given by [14]:

$$
S R R=\frac{|u 1-u 2|}{(u 1+u 2) / 2}
$$

This has a value of 2 in case of second velocity is zero (the ball is not rotate). Table (1) shows the properties of the ball and disc. The ball loaded over a disc by a loads of $(30,40$, $50,60 \mathrm{~N})$. All measurements done at a room temperature $(25 \mathrm{oC})$. The oils used are $(5 \mathrm{~W}-20,10 \mathrm{~W}-30,10 \mathrm{~W}-40$, and $20 \mathrm{~W}-50)$ its dynamic viscosity from [15]. The loaded ball and rotation of the disc surfaces drags oil into the contact and an oil film is formed. Load cells is connected to the computer by an Arduino to measure the friction force. The friction coefficient in the contact region is given as [16]:

$\mu=\frac{F}{W}$

Where $\mathrm{F}$ is the friction force, $\mathrm{W}$ is the applied load. The all conditions of the tests are shown in table (2).

Table 1 Ball and Disc Properties.

\begin{tabular}{|c|c|c|}
\hline Properties & Disc & Ball \\
\hline Material & High carbon Steel & High Carbon Steel \\
\hline Young Modulus & $210 \mathrm{GPa}$ & $210 \mathrm{GPa}$ \\
\hline Poison ratio & 0.33 & 0.33 \\
\hline Speed & $2.5 \mathrm{~m} / \mathrm{s}$ & 0 \\
\hline Radius & $150 \mathrm{~mm}$ & $18 \mathrm{~mm}$ \\
\hline
\end{tabular}

Table 2 Test conditions.

\begin{tabular}{|c|c|}
\hline Conditions & Values \\
\hline Temperature & $25 \mathrm{C}$ \\
\hline Velocity & $1.25 \mathrm{~m} / \mathrm{s}$ \\
\hline equivalent elastic modulus & $2.11 \mathrm{GPa}$ \\
\hline equivalent radius of curvature & $18 \mathrm{~mm}$ \\
\hline
\end{tabular}

\section{RESULTS AND DISCUSSION}

By using different oils and loads, tests have carried out to measure friction force and friction coefficient in point contact EHL. The accuracy of measurements depends on a number of factors. One of the most noticeable is the applied load. The contact load between ball and disc are governing the contact pressure for the test, where higher loads leads to higher contact pressures. A higher contact loads will also cause increase to a higher friction force. The experimental study on this subject are difficult, therefore there are limited number of published researches on this subject. The main difficulty restricting from gaining accurate results is the fluctuating in load readings. This fluctuating results from the vibration of the rig, and high sensitivity of load cell. Thus, to overcome this issue, a method is implemented by averaging all reading for each case, to obtain unique loads result. Here, Excel program is implemented for this sake. The results obtained by developed simple test rig. The skid is supported laterally by a load cell so that the friction force in the disc contact can be measured as reaction force. The reading of load cell are taken to excel to take the average of the reading. Then the coefficient of friction can calculated by equation (4).

When an oil that have a less value of viscosity is used it resulted in a less value of friction coefficient. Friction coefficient increases when replace the oil with oil which 
have a larger value of viscosity. The result show a good agreement with [17]. Figure 3 shows the amounts of friction coefficient were increases with the increases of viscosity of the oils. The viscosity is the resistance to flow or changing the shape of a fluid. It is a factor in fluid friction, so the higher viscosity tend to higher friction.

For the same oil and same conditions, the increasing of applied load leads to increase the friction coefficient. This can be explained by noting that the load (and therefore the contact pressure) has a significant effect on the lubricant viscosity. The increases of pressures in contact area, tend to increase viscosity exponentially. The result show a good agreement with [19]. Figure 4 shows the amounts of friction coefficient were increases with the increases of applied load for same oil and same conditions.

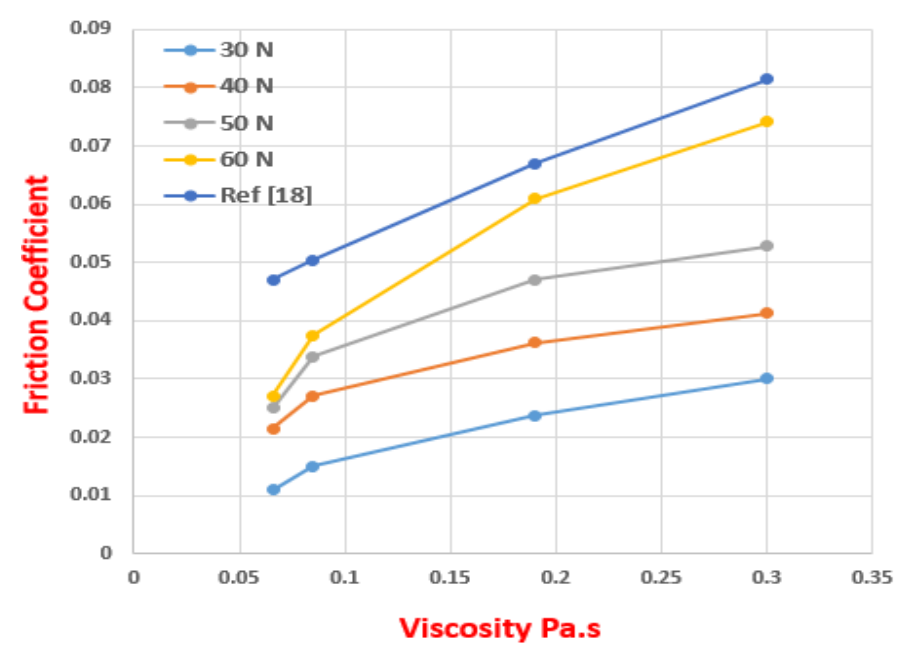

Fig (3) friction coefficient variation with the viscosity.

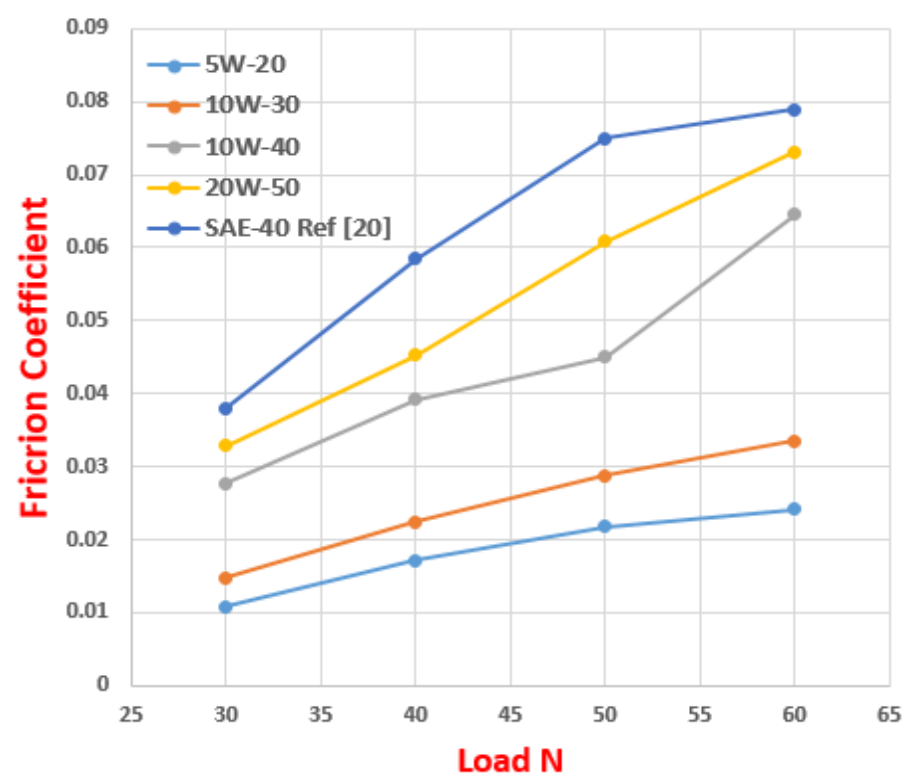

Fig (4) friction coefficient variation with the applied load.

\section{CONCLUSION}

A ball on disc test rig is developed to predict the friction coefficient in point contact EHL. A ball on disc test rig has been used to measure friction in the contact between a steel ball and a steel disc, and thus to showing the variation of friction coefficient with the oil viscosity and applied load. The results shows:
1. The increases in viscosity tend to increases the coefficients of friction approximately in EHL point contact, for the same operating conditions.

2. The coefficients of friction in EHL are increases approximately with the increases of applied load. Because of the increase of pressure in contact area tends to increase the viscosity exponentially with pressure viscosity equation. 
3. The experimental results presented in this study confirm the results of many numerical analysis available in literature.

\section{References:}

[1]. W. Habchi. A Full-System Finite Element Approach to Elastohydrodynamic Lubrication Problem: Application to Ultra-Low-Viscosity Fluids. PhD thesis, University of Lyon, France, 2008.

[2]. Gohar, R. Elastohydrodynamics, second ed. Imperial College Press, London, UK, 2001.

[3]. Svoboda, Petr, David Kostal, Ivan Krupka, and Martin Hartl. "Experimental study of starved EHL contacts based on thickness of oil layer in the contact inlet." Tribology International 67: (2013) 140-145.

[4]. Wang WZ, Wang S, Shi F, Wang YC, Chen HB, Wang $\mathrm{H}, \mathrm{Hu}$ YZ. Simulations and measurements of sliding friction between rough surfaces in point contacts: From EHL to boundary lubrication. Journal of Tribology. 129 (2007) Jul 1:495-501.

[5]. Björling, Marcus. "Friction in Elastohydrodynamic Lubrication." PhD diss., Luleå tekniska universitet, 2014.

[6]. Björling, Marcus, Patrik Isaksson, Pär Marklund, and Roland Larsson. "The influence of DLC coating on EHL friction coefficient." Tribology letters 47, no. 2 (2012): 285-294.

[7]. Björling, Marcus, Roland Larsson, Pär Marklund, and Elisabet Kassfeldt. "Elastohydrodynamic lubrication friction mapping-the influence of lubricant, roughness, speed, and slide-to-roll ratio." Proceedings of the Institution of Mechanical Engineers, Part J: Journal of Engineering Tribology 225, no. 7 (2011): 671-681.

[8]. Cousseau T, Björling M, Graça B, Campos A, Seabra J, Larsson R. Film thickness in a ball-on-disc contact lubricated with greases, bleed oils and base oils. Tribology International; Sep(2012) 53:53-60.

[9]. Hamrock BJ, Dowson D. Isothermal elastohydrodynamic lubrication of point contacts. Part I. Theoretical formulation. Transactions of the ASME, Journal of Lubrication Technology; 98: (1976) 223229.

[10]. De Laurentis, Nicola, Amir Kadiric, Piet Lugt, and Philippa Cann. "The influence of bearing grease composition on friction in rolling sliding concentrated contacts." Tribology international94: (2016) 624-632.

[11]. De Laurentis, Nicola. "An experimental study into the influence of grease composition on friction in EHL contacts." (2016).

[12]. C.E. Goodyer. Adaptive Numerical Methods for Elastohydrodynamic Lubrication. PhD thesis, University of Leeds, Leeds, UK, 2001.

[13]. S. Ahmed, Effcient Finite Element Simulation of Full System Elastohydrodynamic Lubrication Problems (Ph.D. thesis), University of Leeds, Leeds, UK, 2012.

[14]. De Vicente, J., J. R. Stokes, and H. A. Spikes. "The frictional properties of Newtonian fluids in rollingsliding soft-EHL contact." Tribology Letters 20, no. 3 4: (2005) 273-286.

[15]. Shigley, Joseph Edward. "Mechanical engineering design." P635 fig 12.14, 1992.

[16]. Wen S, Huang P. Principles of tribology. Second edition. John Wiley \& Sons; (2017) 2 June.

[17]. Spikes, Hugh. "Basics of EHL for practical application." Lubrication science 27, no. 1: 45-67, 2015.

[18]. Fang, N., et al. "An internal line-contact EHL and traction test rig." SAE transactions (2000): 20902098.

[19]. Mohamed, M. K., A. Alahmadi, W. Y. Ali, and S. Abdel-Sattar. "Effect of magnetic field on the friction and wear displayed by the scratch of oil lubricated steel." International Journal of Engineering \& Technology IJET-IJENS 12, (2012) no. 6.

[20]. Masjedi, M., and M. M. Khonsari. "Theoretical and experimental investigation of traction coefficient in line-contact EHL of rough surfaces." Tribology international 70 (2014): 179-189.

[21]. Z. Hammoudi, and I. Naemah. "Effect of feed rate and rack angle on cutting force and generated temperature in an orthogonal turning process" Diyala Journal of Engineering Sciences, Proceedings of Scientific Conference College of Engineering University of Diyala, Dec. (2015): 706-712

[22]. B. Alwan, M. Jweeg, and Z. Hammoudi "Characteristics Composite Materials to be Used in Trans-Tibial Prosthetic Sockets" Diyala Journal of Engineering Sciences, Vol. 12, No. 02, June (2019): 115-123

Notation

\begin{tabular}{|c|c|c|c|}
\hline $\mathbf{E}$ & The elastic modulus of the materials $(\mathrm{GPa})$. & $\mathbf{V}$ & Poisons ratio. \\
\hline $\mathbf{F}$ & The Friction force $(\mathrm{N})$ & $\mathbf{W}$ & The applied load $(\mathrm{N})$. \\
\hline $\mathbf{h}$ & The oil film thickness $(\mathrm{m})$. & $\mathbf{X}$ & Coordinate in x direction $(\mathrm{m})$. \\
\hline $\mathbf{p}$ & The pressure $(\mathrm{Pa})$. & $\mathbf{Y}$ & Coordinate in y direction $(\mathrm{m})$. \\
\hline $\mathbf{R}$ & The radius of curvature $(\mathrm{m})$. & $\mathbf{Z}$ & Coordinate in z direction $(\mathrm{m})$. \\
\hline $\mathbf{T}$ & The temperature $\left({ }^{\circ} \mathrm{C}\right)$. & $\mathbf{S S R}$ & Slide to roll ratio \\
\hline $\mathbf{u}$ & $\begin{array}{c}\text { The average velocity of the upper and lower } \\
\text { surfaces contacted }(\mathrm{m} / \mathrm{s}) .\end{array}$ & $\boldsymbol{\eta}$ & The oil viscosity $($ Pa.s $)$. \\
\hline $\mathbf{u s}$ & Sliding speed. & $\boldsymbol{\mu}$ & The friction coefficient. \\
\hline
\end{tabular}

